\title{
Studies on Selected Bacteria and Glycolytic Enzyme Activities in the Gut of Eudrilus eugeniae
}

\author{
D.G. Kadam ${ }^{1} *$ and G.R. Pathade ${ }^{2}$ \\ ${ }^{1}$ Department of Microbiology, D.B.F.Dayanand College of Arts and Science, \\ Solapur-413002, Maharashtra, India \\ ${ }^{2}$ Department of Microbiology, H.V. Desai College, Pune, Maharashtra, India \\ *Corresponding author
}

\begin{tabular}{|c|c|}
\hline & A B S T R A C T \\
\hline & \multirow{9}{*}{$\begin{array}{l}\text { Some glycosidic enzymes secreted by the gut of Eudrilus eugeniae and the abundance of } \\
\text { bacteria producing similar enzymes in the gut were studied in order to know the extent of } \\
\text { enzymatic contribution by the worm gut and the ingested bacteria. } 120 \text { different bacteria } \\
\text { were isolated from the worm gut and their enzymatic activities were detected by using } \\
\text { respective media and reagents. In vitro gut wall tissue culture of various gut portions was } \\
\text { done to assess enzymatic activities in gut wall and in the culture medium. The total viable } \\
\text { counts of bacteria decreased in the crop / gizzard portion and increased gradually in the } \\
\text { posterior region (midgut }+ \text { hindgut) of the gut by about two thousand times more than } \\
\text { those in the anterior gut. In vitro tissue culture of gut wall showed that E. eugeniae } \\
\text { produced different extracellular as well as intracellular enzymes for degradation of the } \\
\text { substrates used. However, for certain glycosidic substrates viz. starch and chitin, enzyme } \\
\text { activities by the worm itself were relatively low while the abundance of corresponding } \\
\text { glycolytic bacterial group was more indicating probable role of the gut bacterial flora in } \\
\text { substrate degradation upon selective proliferation of specific bacterial group in the gut of } \\
\text { the earthworm. The results indicate that the degradation of certain substrates like starch } \\
\text { and chitin might be enhanced by the ingested bacterial flora present in the feed material } \\
\text { particularly in the foregut region of the earthworm gut. }\end{array}$} \\
\hline Keywords & \\
\hline & \\
\hline & \\
\hline Gut tissue culture. & \\
\hline Article Info & \\
\hline $\begin{array}{l}\text { Accepted: } \\
20 \text { March } 2017\end{array}$ & \\
\hline $\begin{array}{l}\text { Available Online: } \\
10 \text { April } 2017\end{array}$ & \\
\hline & \\
\hline
\end{tabular}

\section{Introduction}

The earthworms feed on organic materials, fragment and digest them in the gut by their own enzymes and with the help of ingested microorganisms, and excrete nutritionally rich feces or casts. When earthworms feed on organic matter, they ingest many microorganisms, some of which are digested by the worms. However, certain survived organisms grow and flourish when the casts are excreted (Dash et al., 1984; Lee, 1985; Edward, 1988; Tiwari et al., 1990). The enzymatic activities like cellulase, amylase, protease, chitinase etc. have been studied in the Lumbricidae family (Laverack, 1963; Tracey 1951). In temperate zones, studies on earthworm digestive enzyme activities have been conducted only in the Lumbricidiae family (Garvin et al., 2000). It is further reported that the quantitative studies on digestive enzymatic activities have also been limited to certain types of enzymes only in limited earthworm families (Tracey, 1951; 
Parle, 1963; Urbazek, 1990). Origin and activities of digestive enzymes in the gut and tissue culture of different tropical geophagus earthworms have been reported (Lattaud et al., 1997, 1998). There are almost no data on other families (Garvin et al., 2000). Further reports indicate that the quantitative studies on digestive enzymatic capabilities of epigeic earthworms are also scanty (Parthasarathi and Ranganathan, 1999; Rangnathan and Vinotha 1998; Parthasarathi, 2000). The studies carried out so far are inadequate to arrive at conclusions about origin of the enzyme activities of earthworms (Kumar et al., 2010; Shweta, 2012). Therefore, the present investigations were aimed to study selected glycolytic activities in the gut of Eudrilus eugeniae and to determine whether some of these enzymes were produced by the worm itself or contributed also by the microorganisms ingested with their feed. For this, glycosidic enzyme activities in gut (both wall and content) were studied and abundance of corresponding bacterial biochemical groups was determined in terms of percentages of CFUs/ml of each group.

\section{Materials and Methods}

Microbiological media: Plate count agar, Starch agar, Cellulose agar, Chitin agar and Pectin agar

Biochemical media - Maltose and cellobiose

Materials used for tissue culture and mutualism studies - Adult earthworms of Eudrilis eugeniae (Kinberg)

Tissue Culture Medium - Grace's medium (modified)

Antibiotics - Amphotericin B and Sodium benzyl penicillin

Holtfreter solution, $\mathrm{CO}_{2}$ Incubator

Enzyme assay materials

Oligosaccharides: Maltose, Cellobiose, Polysaccharides - Starch, Cellulose, Chitin
Reagents for protein estimation and Bovine serum albumin (Lawry et al., 1951)

Reagents for Dinitrosalicylic acid method of sugar estimation (Miller et al., 1959)

Dialysis membrane (egg shell membrane)

\section{Methods}

\section{Determination of total viable counts of bacteria}

Total viable counts of bacteria present in partially decomposed tendu leaf feed, in gizzard, fore gut, mid gut and hind gut of the earthworm were determined by spreading 0.1 $\mathrm{ml}$ amount of dilutions of the feed and gut contents collected from respective parts of gut on sterile Plate count agar plates and incubating at $28^{\circ} \mathrm{C}$.

\section{Degradative and enzymatic studies of isolates}

All bacterial isolates were studied to detect their ability to secrete different hydrolytic enzymes. For this, different nutritional media were used. Specific substrates for the specific enzymes were incorporated in those media. For bacterial isolates, inoculum was prepared by mixing small portion of a well isolated, 24 $\mathrm{h}$ old colony in small amount of sterile saline in a tube. A loopful of inoculum of each isolate was inoculated aseptically on specific media by spot inoculation. All the plates were incubated at room temperature for required period of time. After incubation the zones of hydrolysis were detected visibly or by adding specific reagents on the media surface or by observing change in color of indicator present in the medium.

\section{Earthworm gut tissue culture}

The glycolytic enzyme activities were measured in the whole gut (gut wall with contents); in the cultured gut tissues and also 
in the tissue culture media order to determine type and origin of the enzymes.

\section{Enzyme activities in the whole gut (wall +} contents)

Ten adult earthworms were washed with sterile distilled water. The worms were dissected in ice-cold Holtfreter solution $(8.77 \% \mathrm{Nacl}, \mathrm{W} / \mathrm{V})$. Guts of all the worms were removed. Each gut was divided into two parts - anterior part and posterior part. From anterior part, the crop and the gizzard potion was removed for use. The posterior part was divided into three equivalent parts - foregut, midgut and hindgut. All the gut regions were collected separately in $10 \mathrm{ml}$ phosphate buffer, $\mathrm{pH} 7.0$ and homogenized in homogenizer. The homogenate from each tube was then centrifuged at $5000 \mathrm{rpm}$ for 10 min. The supernatants of each tube were dialyzed against phosphate buffer at $21.0^{\circ} \mathrm{C}$ for $24 \mathrm{hr}$ and retentate was used as source of enzyme for assay.

\section{In vitro culture of earthworm guts wall tissue}

Ten, adult worms were placed in cellulose wool soaked in Holtfreter solution for $24 \mathrm{hr}$. Then the worms were placed in cellulose wool soaked in amphotericin B $(25 \mu \mathrm{g} / \mathrm{ml})$ in phosphate buffer $\mathrm{pH} 7$ for five hr. All the worms were then dissected in Holtfreter solution under aseptic conditions. The gut was divided into four sections as described above. All the gut regions were pooled separately and placed separately in sterile Holtfreter solution containing sodium benzyl penicillin (100 U/ml) and streptomycin $(2 \mu \mathrm{g} / \mathrm{ml})$ for 15 min. These explants were then placed separately in sterile tissue culture dishes containing $15.0 \mathrm{ml}$ sterile Grace's tissue culture medium containing amphotericin B and sodium benzyl penicillin. Lids of all the culture dishes were sealed with cellophane tape and were incubated in $\mathrm{CO}_{2}$ incubator at $25^{\circ} \mathrm{C}$ for 5 days. After incubation, samples of tissue fragments and culture media were removed. Enzyme solutions from the tissue fragments were prepared as described above for whole gut (wall + gut contents). Gut wall tissues were crushed in $5 \mathrm{ml}$ of phosphate buffer, $\mathrm{pH}$ 7.0., centrifuged, dialyzed and used as enzyme source. For the enzyme activities secreted in the culture media, the media were directly dialyzed and the retentate was used as enzyme source for determination of enzyme activities secreted in the tissue culture medium.

\section{Enzyme assays}

The various glycosidic substrates used for enzyme assays were - Starch, Cellulose (Carboxy methyl cellulose), Chitin, Maltose, and Cellobiose. The glycolytic enzyme activities were determined by GOD/POD method (Span diagnostics Surat, India) except for chitin which was done by dinitrosalisylic method (Miller et al., 1959).

The specific glycolytic enzymatic activities were expressed as $\mu \mathrm{g}$ glucose released per milligram of protein per minute. The glycolytic activities in the culture media were expressed as total activity ( $\mu \mathrm{g}$ glucose released per minute). The protein content of all enzyme preparations was estimated by the method of Lowry et al., (1951) by using bovine serum albumin as the standard protein.

\section{Statistical analysis}

Data reported here are the means of three replicates $(n=3)$. The estimated microbial populations and the enzyme activities are expressed as the Mean \pm S.E. The difference in the mean values of microbial populations and enzyme activities were tested for their statistical significance using students' ' $t$ ' test. 


\section{Results and Discussion}

Total viable counts of bacteria in the feed, in gizzard, in for gut, mid gut and hind gut of Eudrilus eugeniae are presented in table 1 . The total viable counts of bacteria in the feed were considerably high. After the earthworm consumed the feed material, the total viable counts of bacteria in it went on changing along the passage through digestive tract of the earthworm. The total viable counts of bacteria significantly $(\mathrm{p} \leq 0.5)$ decreased in the crop / gizzard portion of the digestive tract. The total viable counts still further decreased in the fore gut. This indicated that the earthworm might have digested some of the bacteria ingested through the feed material. The total viable counts of bacteria, however, increased significantly $(p \leq 0.5)$ in the posterior region of the gut. The total viable count of bacteria increased by more than two thousand times in the posterior gut than those found in the fore gut. Thus, it seemed that there might be suitable environment for growth of the survived bacteria when they reached the posterior gut (midgut + hindgut).

\section{Degradative and enzymatic studies}

Figure 1 shows that most of the bacterial isolates produced catalase and oxidase enzymes. This is suggestive of aerobic/ facultative anaerobic metabolic activities of the bacteria. Amongst the remaining groups the dominant type was amylase producers $(72 \%)$. Cellulase producers $(25 \%)$ were relatively low in numbers in the gut contents. The large number of isolates producing amylase enzyme highlights their role in decomposition of starch containing plant residues. Though Cellulose is the most abundant polysaccharide found in plant tissues, the percentage of cellulase producing isolates $(25 \%)$ was relatively low. This might be because the cellulase is an enzyme complex that contains group of enzymes acting on cellulose molecule. Only the true cellulolytic microbial population can attack the native cellulose molecule and other noncellulolytic microorganisms might utilize the products or intermediates of enzymatic action of true cellulolytic population. The percentage of chitinase producing isolates $(65 \%)$ was also considerable, though the chitin content of plant residues is very low. The presence of high number of chitinase producers might be due to presence of chitin that arises from two major sources -from the plant cell walls and cell walls of dead or damaged fungi during gut passage. The number of pectinase producing bacterial isolates (28\%) was also found to be lower and it correlates well with the relative amount of pectin present in the plant tissue debris.

\section{Specific glycolytic activities in the whole gut (wall + content)}

The specific activities of glycolytic enzymes in the whole gut are presented in table 2 . Eudrilus engeniae was able to degrade all the substrates studied. In general the enzyme activities in the anterior part of gut (crop + gizzard) were low. The highest enzyme activities were found in the foregut while the lowest enzyme activities were found in the hindgut. The amylase activity was highest in the foregut followed by mid gut and anterior part of gut (crop + gizzard). The lowest amylase activity was detected in the hindgut. Among the polysaccharidases studied, the lowest enzymatic activity was found on cellulose. The cellulase activity was highest in the fore gut and lowest in the hindgut. Considerably significant chitinase activities were detected in the whole gut. The chitinase activity was highest in the foregut followed by the anterior part of the gut. The lowest chitinase activity was found in the hindgut.

Among the oligosaccharides studied, the highest enzyme activity was detected on 
maltose. The maltase activity was highest in the foregut followed by anterior part $(\mathrm{c}+\mathrm{g})$ of the gut. The lowest maltase activity was detected in the hindgut. The cellobiase activity was significantly $(\mathrm{p} \leq 0.5)$ higher than cellulase in all the parts of the gut.

\section{Specific enzyme activities in tissue culture}

The data on the specific glycosidic activities detected in tissue culture of various parts of gut are presented in table 3. Activities of glycosidic enzymes for hydrolysis of all the substrates studied were present in all the cultured parts of the gut tissue. However, these enzyme activities were significantly ( $\mathrm{p} \leq$ $0.5)$ lower than those detected in the whole gut (wall+contents).

Among the oligosaccharides studied the maximum glycosidic enzyme activities were detected on maltose. The highest enzyme activity of maltose hydrolysis was detected in anterior gut followed by foregut. The enzyme activities on maltose were almost same in complete posterior gut i.e. foregut, midgut and hindgut. The enzyme activities on cellobiose were significantly $(p \leq 0.5)$ lower than that on cellulose in tissue culture. In tissue culture, the highest enzyme activity on cellobiose was detected in anterior gut followed by fore gut. The cellobiase activities in the mid gut and hindgut were the weakest amongst all.

Among the polysaccharides studied, the maximum glycosidic enzyme activities were detected on starch in tissue culture. But these activities were significantly $(\mathrm{p} \leq 0.5)$ lower than those detected in whole gut. In tissue culture, amylase activity was maximum in the anterior gut (crop + gizzard) followed by foregut. In fact, the amylase activity in all the three parts of posterior gut viz. Foregut, midgut and hindgut were almost same. This is contrary to the amylase activity detected in the whole gut where it decreased from foregut to hindgut. The glycosidic enzyme activities on cellulose were mainly confined to the parts of posterior gut viz. foregut, midgut and hindgut. The maximum cellulase activity was detected in foregut followed by midgut and hindgut. Among all the polysaccharides tested, glycosidic activity on chitin was lowest, but it was detected in all parts of the gut cultured. Thus, though all the polysaccharide substrates studied were degraded in all parts of gut to varying levels, the polysaccharidases activities were significantly $(\mathrm{p} \leq 0.5)$ lower than those in the whole gut.

Table.1 Total viable counts of bacteria in partially decomposed tendu leaf residues, gizzard+crop, anterior gut and posterior gut of Eudrilus eugeniae

\begin{tabular}{|l|l|}
\hline Source & $\begin{array}{l}\text { TVC of Bacteria } \\
(\mathrm{CFUs} / \mathrm{g})\end{array}$ \\
\hline $\begin{array}{l}\text { Partially decomposed tendu leaf } \\
\text { residues }\end{array}$ & $3.26 \pm 0.12 \times 10^{7}$ \\
\hline Gizzard + Crop & $7.25 \pm 0.30 \times 10^{5}$ \\
\hline Fore gut & $0.4 \pm 0.01 \times 10^{5}$ \\
\hline Mid gut & $2.86 \pm 0.2 \times 10^{5}$ \\
\hline Posterior gut & $10.48 \pm 0.2 \times 10^{5}$ \\
\hline
\end{tabular}

TVC: Total viable count 
Table.2 Enzyme activities in the whole gut (wall and contents) of Eudrilus eugeniae Mean of two independent assays \pm standard error

\begin{tabular}{|l|l|l|l|l|}
\hline \multirow{2}{*}{ Carbohydrate } & \multicolumn{4}{|l|}{ *S.A.in whole gut } \\
\cline { 2 - 5 } & \# c+g & Foregut & Midgut & Hindgut \\
\hline Cellulose & $7.95 \pm 0.03$ & $16.93 \pm 0.11$ & $6.42 \pm 0.02$ & $4.30 \pm 0.02$ \\
\hline Cellobiose & $8.42 \pm 0.03$ & $20.18 \pm 0.14$ & $9.59 \pm 0.1$ & $4.28 \pm 0.04$ \\
\hline Starch & $21.29 \pm 0.02$ & $42.68 \pm 0.02$ & $25.11 \pm 0.04$ & $14.62 \pm 0.05$ \\
\hline & $17.04 \pm 0.04$ & $27.55 \pm 0.16$ & $10.61 \pm 0.07$ & $6.32 \pm 0.01$ \\
Maltose & & & & \\
\hline Chitin & $11.63 \pm 0.07$ & $23.36 \pm 1.2$ & $8.46 \pm 0.02$ & $5.81 \pm 0.1$ \\
\hline
\end{tabular}

*S.A. $=$ specific glycosidic activity expressed as $\mu \mathrm{gs}$ glucose released $\mathrm{mg}^{-1}$ protein $\mathrm{min}^{-1}$. \# c-crop; g-gizzard.

Table.3 Enzyme activities in cultured tissues of gut wall of Eudrilus eugeniae. Mean of two independent assays \pm standard error

\begin{tabular}{|l|l|l|l|l|}
\hline \multirow{2}{*}{ Carbohydrate } & \multicolumn{4}{|l|}{ *S.A.in tissue culture } \\
\cline { 2 - 5 } & $\# \mathrm{c}+\mathrm{g}$ & Foregut & Midgut & Hindgut \\
\hline Cellulose & $1.24 \pm 0.01$ & $2.0 \pm 0.01$ & $1.63 \pm 0.02$ & $1.02 \pm 0.01$ \\
\hline Cellobiose & $1.04 \pm 0.01$ & $0.55 \pm 0.02$ & $0.26 \pm 0.01$ & $0.20 \pm 0.03$ \\
\hline Starch & $1.98 \pm 0.1$ & $1.85 \pm 0.2$ & $1.80 \pm 0.02$ & $1.79 \pm 0.2$ \\
\hline Maltose & $3.87 \pm 0.1$ & $3.26 \pm 0.1$ & $3.26 \pm 0.1$ & $3.21 \pm 0.01$ \\
\hline Chitin & $0.98 \pm 0.03$ & $1.64 \pm 0.02$ & $1.01 \pm 0.3$ & $0.53 \pm 0.1$ \\
\hline
\end{tabular}

*S.A. $=$ specific glycosidic activity expressed as $\mu$ gs glucose $\mathrm{mg}^{-1}$ protein $\mathrm{min}^{-1}$. \# c-crop; g-gizzard.

Table.4 Enzyme activities in the cultured media of gut tissue culture of Eudrilus eugeniae. Mean of two independent assays \pm standard error

\begin{tabular}{|l|l|l|l|l|}
\hline \multirow{2}{*}{ Carbohydrate } & *T.A.in culture media & \\
\cline { 2 - 5 } & \# c $+\mathrm{g}$ & Foregut & Midgut & Hindgut \\
\hline Cellulose & $5.9 \pm 0.01$ & $4.3 \pm 0.01$ & $4.8 \pm 0.02$ & $3.9 \pm 0.02$ \\
\hline Cellobiose & $7.60 \pm 0.02$ & $5.8 \pm 0.01$ & $5.3 \pm 0.01$ & $5.3 \pm 0.04$ \\
\hline Starch & $5.9 \pm 0.07$ & $4.6 \pm 0.24$ & $4.4 \pm 0.1$ & $4.2 \pm 0.03$ \\
\hline Maltose & $7.3 \pm 0.05$ & $5.9 \pm 0.07$ & $5.4 \pm 0.4$ & $5.0 \pm 0.03$ \\
\hline Chitin & $4.5 \pm 0.02$ & $4.3 \pm 0.03$ & $4.2 \pm 0.03$ & $3.1 \pm 0.07$ \\
\hline
\end{tabular}

*T.A. - total activity, total glycosidic activity expressed as $\mu$ gs glucose $\min ^{-1}$. \# c-crop; g-gizzard. 
Figure.1 Percentages of bacterial isolates producing enzymes

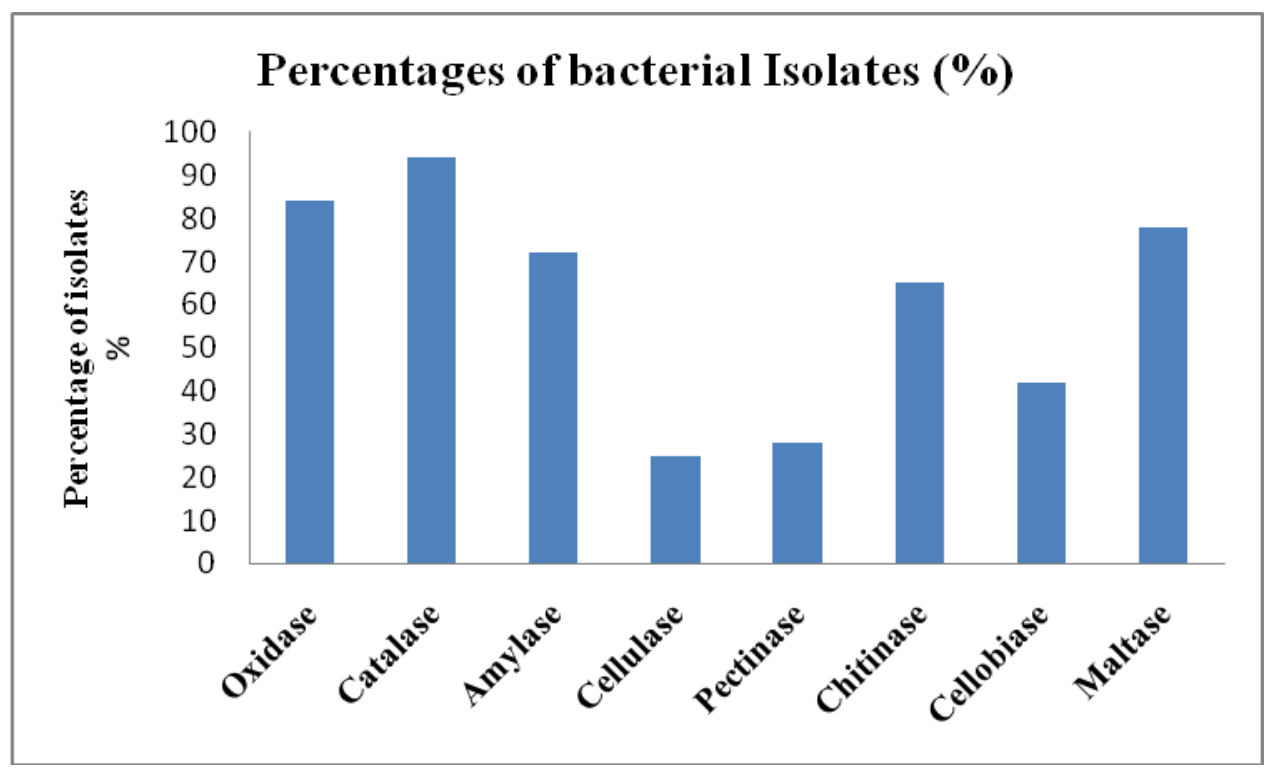

\section{Total activities in culture media}

The enzyme activities in tissue culture media are expressed as total activity of culture medium ( $\mu$ gs of reducing sugar released per minute). In general, the glucosidic enzyme activities on all the substrates were significantly $(p \leq 0.5)$ greater in the culture media than those in the cultured tissues (Table 4).

Amongst the polysaccharides studied the maximum glycosidic activity was detected on cellobiose in anterior gut and then it decreased in foregut and hindgut. The glycosidic enzyme activities on cellulose and cellobiose in culture media were more or less same. Likewise, the glycosidic enzyme activities on starch and maltose were more or less same but the maltase activity was only slightly greater. The chitinase activity detected in anterior gut, midgut and foregut were almost similar. The minimum chitinase activity was detected in the hind gut.

The results suggested that the earthworm Eudrilus eugeniae, which is an epigeic species, has a wide glucosidic enzyme system. At least, all the substrates used in present investigations were utilized by the earthworm with varying capabilities.

The present studies on the origin of some glycosidic enzyme activities in the earthworm Eudrilus engeniae indicated that this earthworm had complete but just enough enzyme activities required for degradation certain glycosidic substrates but much lower and inadequate for certain other substrates compared to even endogeic geophagus earthworm. The glycosidic substrates used during present studies are characteristic of plant materials. Those substrates which were degraded more readily in the gut confirm that this earthworm species feeds on vegetal components and plant remains present in soil. The enzymatic studies on whole gut showed that starch and maltose were degraded particularly more readily by the worm indicating their wide preference for feed substrates of plant origin. Considerably high enzyme activity was also detected on chitin suggesting digestion of fungal component of the feed material by the worm. The glycosidic enzymatic activities for most of the substrates tested were found to be in the foregut region 
of the gut worm. Comparison of enzyme activities on cellulose and cellobiose in whole gut showed that the glycosidic enzyme activities on cellobiose were significantly $(\mathrm{p} \leq$ $0.5)$ higher than those detected on cellulose. Comparison of enzyme activities on starch and maltose in whole gut showed that the glycosidic activities on maltose were significantly $(p \leq 0.5)$ lower than those detected on starch.

Gut wall tissue culture showed that the glycosidic enzyme activities on all the substrates tested were detectable in all the cultured parts of gut, though much lower than those in the whole gut. This showed that Eudrilus eugeniae was able to synthesis all the enzymes required for utilization of substrates tested. However, enzyme activities detected in tissue culture on certain substrates tested were much lower and might be inadequate for rapid and voracious feeding habit of Eudrilus eugeniae. Comparison between the glycosidic enzyme activities in cultured gut tissues with those in whole gut revealed certain important facts. Thus, cellobiase activities were significantly $(\mathrm{p} \leq$ $0.5)$ lower than cellulase activities in gut tissue culture and higher than cellulase activity in the whole gut as well as culture media. Further, maltase activity was higher than amylase in the cultured tissues and culture media and lower than amylase in the whole gut. Moreover, maximum activities of both amylase and maltase were detected in the anterior gut $(\mathrm{c}+\mathrm{g})$ in cultured tissue while these activities were maximum in foregut region in whole gut. Thus, cellulase, cellobiase, amylase and maltase activities in cultured tissues were highest in anterior gut and then gradually decreased up to the hindgut while these activities were lower in anterior gut and then increased from anterior gut up to fore gut in whole gut and then decreased towards hindgut. This trend is suggestive of probable contribution by ingested bacteria in degradation of these substrates in anterior gut, foregut, midgut and hindgut of the earthworm. Chitinase activities in the cultured tissues were significantly $(\mathrm{p} \leq$ $0.5)$ lower than those in whole gut which is also indicative of microbial participation in degradation of chitin containing components of feed.

Comparison of glycosidic activities in the cultured tissues with their corresponding culture media showed that both the polysaccharidase and oligosaccharidase activities were present in each cultured gut region and their corresponding culture media. The total glycosidic activities for each glucosidic substrate were however greater in the culture media. This indicated that all the studied glycosidic activities of Eudrilus eugeniae were extracellular. Maltase and cellobiase were major glucosidic activities in cultured media.

In conclusion Eudrilus eugeniae secreted essential glucosidic enzyme activities intracellularly as well as extracellularly for degradation of substrates used in varying quantities in different regions of gut.

The total viable counts of bacteria (CFUs/ml) in various regions of gut indicated that the earthworm might digest certain bacteria during gut passage and some of the survived bacterial groups might flourish differentially and dominate in the gut population. Such bacterial flora might contribute to the enzymatic digestion of certain substrates such as starch and chitin in the feed material. Complete unraveling of digestive capabilities needs further studies.

\section{References}

Dash, H.K., Beura, B.N. and Dash, M.C. 1986. Gut load, transit time, gut micro flora and turnover of soil, plant and fungal material by some tropical earthworms. 
Pedobiologia, 29: 13-20.

Edwards, C.A. 1995. Historical overview of vermicomposting. Biocycle. Journal of Composting and Recycling, 36: 56-58.

Edwards, C.A. and Fletcher, K.E. 1988. Interactions between earthworm and microorganisms in organic matter breakdown. Agri. Ecosystems and Environ., 24: $235-247$.

Garvin, M.H., Lattaud, C., Trigo, D. and Lavelle, P. 2000. Activity of glycolytic enzymes in the gut of Homogaster elisae (Oligochaeta, Hormogastridae. Soil Biol. Biochem., 32: 929- 934.

Kumar, Rahul., Singh, B.L. and Shweta. 2010. Enzyme activities and microflora of earthworm gut and vermireactors as indicators of the stabilization of wastes degradation pro less. Bioremedation J., 14(3): 150-157.

Lattaud, C., Locati, S., Mora, P. and Rouland, C. 1997. Origin and activities of glycolytic enzymes in the gut of the tropical geophagus earthworm Millsonia anomala from Lamto (ĉote d'Ivoire. Pedobiologia, 41: 242-251.

Lattuad, C., Locati, S., Mora, P., Rouland, C. and Lavelle, P. 1998. The diversity of digestive systems in tropical geophagus earthworm. Appl. Soil Ecol., 9: 189-195.

Lattuad, C., Mora, P., Garvin, M., Locati, S. and Rouland, C. 1999. Enzymatic digestive capabilities in geophagous earthworms: Origin and activities of cullulolytic enzymes. Pedobiologia, 43(6): 842 - 850.

Lattuad, C., Zang, B.G., Locati, S. and Rouland, C. 1997. Activities of the digestive enzymes in the gut and in tissue culture of a tropical geophagus earthworm Polypheretima elongata (Megascolecidae. Soil Biol. Biochem., 29: 335 - 339.

Laverack, M.S. 1963. The physiology of earthworms. In: Kerkut, A.G.(ed) International Series Monograph on Pure and Applied Biology. Pergamon Press, Oxford. pp. 18-23.

Lowry, O.H., Rose brough, N.J., Farr, A.L. and Rall, R.J. 1951. Protein measurement with the Folin phenol reagent. J. Biol. Chem., 193: 265-275.

Parle, J.N. 1963. A Microbiological study of earthworm casts. J. General Microbiol., 31: 13-22.

Parle, J.N. 1963. Microorganisms in the intestine of the Earthworms. J. General Microbiol., 31: pp.1- 11 .

Parthasarathi, K. and Ranganathan L.S. 1999. Longevity of microbial and enzyme activity and their influence on NPK content in press mud vermicasts. European J. Soil Biol., 35(3): $107-113$.

Parthasarathi, K. and Ranganathan, L.S. 1998. Press mud vermicasts are the 'hot spots' of fungi and bacteria. Ecol. Environ. Conser., 4(3): 81-86.

Parthasarathi, K. and Ranganathan, L.S. 2000. Ageing effect on enzyme activities in press mud vermicasts of Lampito mauritii (kinberg) and Eudrilus eugeniae (kinberg. Biol. Fertility of Soils, 30(4): 347 - 350.

Tiwari, S.C., Tiwari, B.K. and Mishra, R.R. 1990. Micro fungal species associated with the gut content and casts of Drawida assamensis. Gates. Proc. Indian Acad. Scri. Plant Sci.), 100: pp 379-382.

Urbasek, F. 1990. Cellulase activity in the gut of some earthworms. Rev. Ecol. Biol. Soil., 27: pp 21-28.

Urbasek, F. and Pizl, V. 1991. Activity of digestive enzymes in the gut of five earthworm species (Oligochaeta: Lumbricidae) Rev. Ecol. Biol. Soil., 28, 461- 468.

\section{How to cite this article:}

Kadam, D.G. and Pathade, G.R. 2017. Utilization of Mango Peel Powder (MPP) in Mango Nectar Formulation. Int.J.Curr.Microbiol.App.Sci. 6(4): 2256-2264.

doi: https://doi.org/10.20546/ijcmas.2017.604.262 